\title{
CONSIDERAÇÕES SOBRE A CRÍTICA DE ARTE A PARTIR DA METAFÍSICA DO BELO DE SCHOPENHAUER
}

\author{
Nathan Menezes Amarante Teixeira ${ }^{1}$ \\ Universidade Federal Fluminense (UFF)
}

\begin{abstract}
RESUMO:
Buscamos aqui fundamentalmente pensar como podemos encontrar, em meio às considerações gerais de Schopenhauer sobre a arte em sua Metafísica do Belo, indicações acerca do que podemos compreender como crítica de arte. Deste modo, não serão feitas aqui alusões ao conceito de crítica de arte presente em outros autores ou outros contextos; limitaremosnos apenas a apresentar o que podemos compreender acerca da crítica de arte a partir das implicações estéticas que o pensamento schopenhauereano nos coloca, especificamente a partir da compreensão da obra de arte como possibilidade de conhecimento das Ideias.
\end{abstract}

PALAVRAS- CHAVE: Schopenhauer; Metafísica do Belo; Ideias; Crítica de Arte.

\section{CONSIDERATIONS ABOUT ART CRITICISM SINCE SCHOPENHAUER'S METAPHYSICS OF BEAUTIFUL}

\begin{abstract}
:
We seek fundamentally here think how we can find, amid Schopenhauer's general considerations about art in his Metaphysics of Beautiful, indications about of we can understand as art criticism. By this mean, it will not be made here allusions to the concept of art criticism found in other authors or other contexts; we will limit ourselves only to present what we can understand about art criticism from the aesthetic implications that the schopenhaurean thought puts to us, specifically from the understanding of the work of art as possibility of knowledge of Ideas.
\end{abstract}

\footnotetext{
${ }^{1}$ Mestrando em Filosofia pela Universidade Federal Fluminense (UFF), Rio de Janeiro Brasil. E-mail: nathan.menezes.teixeira@ hotmail.com.
} 
KEY-WORDS: Schopenhauer; Metaphysics of Beautiful; Ideas; Art Criticism.

Metafísica do Belo é o termo empregado por Schopenhauer para abarcar o todo das suas considerações acerca da arte, presentes no Livro III e nos complementos ao mesmo encontrados respectivamente nos Vols. I e II de $O$ mundo como vontade e representação, e nas preleções de Schopenhauer lidas por ele em 1820 na Universidade de Berlim nomeadas justamente pelo termo em questão. Porém, fundamentalmente, tal designação diz respeito à "doutrina da representação na medida em que esta não segue o princípio de razão, é independente dele, ou seja, a doutrina das Ideias, que são justamente o objeto da arte" (SCHOPENHAUER, 2001, p. 23).

De início temos a afirmação basilar da estética de Schopenhauer, de que a arte é fundamentalmente apresentação de Ideias. Sentimos a devida significação deste pensamento quando nos atentamos para o fato de que, para Schopenhauer, a perspectiva habitual a partir da qual olhamos o mundo é aquela em que nosso intelecto encontra-se subordinado à Vontade, ao ímpeto cego contínuo que Schopenhauer identifica como descortinável por qualquer sujeito do conhecimento na medida em que é individuo, ou seja, possui um corpo enquanto lugar singular em que este ocupa o mundo. No corpo somos objetivações da Vontade, somos o fenômeno do querer tornado objeto, "logo, todo o corpo não tem de ser outra coisa senão minha vontade que se torna visível, tem de ser minha vontade mesma na medida em que esta é objeto intuível" (SCHOPENHAUER, 2005, §20, p. 165).

$\mathrm{O}$ intelecto a serviço da Vontade toma todas as suas representações enquanto motivos, que movem a Vontade na medida em que para esta são interessantes, onde vemos que a representação do mundo segundo o princípio de razão, que dá conta dos fenômenos apenas enquanto ocorrências que possuem uma causa de assim serem, é sempre condicionada por esse interesse volitivo. A singularidade e vivacidade dos objetos enquanto objetivações da Vontade perdem-se sempre no processo representacional padrão que realizamos enquanto indivíduos, de modo que perdemos sempre aquilo que ele pode ser em si, caso estivesse livre das cadeias de relações causais do principio de razão. Precisando mais, a Vontade entra em cena gradativamente no cenário que a representação lhe dá constituindo os diversos reinos da natureza, isso a partir dos "atos originários" que são as Ideias. As Ideias mostram-se então como as primeiras movimentações da Vontade que a individualiza inicialmente, comportando características que serão sempre repetidas nas ocorrências individuais dos objetos em relação à Ideia específica à qual cada um deles corresponde, sendo esta sua essência.

São por fim as Ideias que permanecem veladas para o olhar que se guia segundo o princípio de razão, e são justamente estas o objeto da arte 
conforme dito aqui inicialmente. Ou seja, para Schopenhauer, cabe à arte apresentar o conteúdo mais vivo e significativo que se expressa continuamente nos fenômenos, e que permanece esquecido na cotidianidade. Repetindo o que dissemos mais à cima, a compreensão da arte enquanto apresentação de Ideias é central na Metafísica do Belo de Schopenhauer, pois confere a esta um caráter fundamentalmente cognitivo e privilegiado ao ter na contemplação das Ideias sua origem e a comunicação destas como finalidade; por isso ainda é que Schopenhauer afirma "consideramos o belo como um conhecimento em nós, um modo todo especial de conhecer, e nos perguntamos que esclarecimentos esse modo de conhecer nos fornece acerca do todo de nossa concepção de mundo" (SCHOPENHAUER, 2001, p. 25).

$\mathrm{O}$ conhecimento das Ideias proporcionado pela arte seria a ocorrência do Belo, a partir da transformação do objeto singular em sua Ideia e da mudança necessária ocorrida no indivíduo para que este contemple a mesma. Schopenhauer diz:

Quando elevados pela força do espírito, abandonamos o modo comum de consideração das coisas, cessando de seguir apenas suas relações mutuas conforme o princípio de razão, cujo fim último é sempre a relação com a própria vontade; logo, quando não mais consideramos o Onde, o Quando, o Porquê e o Para quê das coisas, mas única e exclusivamente seu QUÊ [...] o que é conhecido não é mais a coisa particular enquanto tal, mas a IDEIA, a forma eterna, a objetidade imediata da Vontade neste grau. Justamente por ai, ao mesmo tempo, aquele que foi tomado na intuição não é mais indivíduo, [...] e sim o atemporal PURO SUJEITO DO CONHECIMENTO destituído de Vontade e sofrimento (SCHOPENHAUER, 2005, §34, p. 246).

Se o objeto dá-se sempre a um sujeito cujo intelecto está restrito à consideração interessada e apressada do princípio de razão, e é essa configuração que encobre a Ideia, cumpre que para o aparecimento da última outra relação entre conhecedor e conhecido seja dada ${ }^{2}$. Logo, cumpre que não haja mais um indivíduo, mas o sujeito do conhecimento livre da condução da Vontade que por isso não se coloca fixo frente a algo a ser conhecido, mas dissolve-se em uma Ideia, pois "toda a consciência é integralmente assaltada e preenchida por uma única imagem intuitiva"

\footnotetext{
${ }^{2}$ Melhor explicando, tomemos a afirmação de John Atwell: "Existem Ideias apenas para o puro sujeito do conhecimento, e existe o puro sujeito do conhecimento apenas para as Ideias. O conhecedor puro e os objetos puros são noções correlativas, consequentemente não é o caso de que ambos acarretam um ao outro; nem, é claro, é o caso de que existe um sem o outro. Conhecedor puro e objetos puros 'surgem' simultaneamente, e correlativamente" (ATWELL, 1995, p. 142). Ou seja, para que hajam Ideias a serem apreendidas, deve sempre haver algum intelecto que deslocou-se de seu modo de funcionamento cotidiano e considerou os objetos livre do principio de razão.
} 
(Ibidem, §34, p. 246). Schopenhauer descreve de modo preciso tal modo de consideração proporcionado pela experiência do Belo, chamando-o de genial, em oposição ao meramente racional. Assim, ele diz que:

O modo de consideração que segue o princípio de razão é o racional, único que vale e ajuda na prática e na ciência; já o modo que prescinde do conteúdo deste princípio é o genial, único que vale e ajuda na arte. [...] O primeiro é comparável a uma tempestade violenta que desaba sem princípio e sem fim, a tudo verga, movimenta e arrasta; o segundo ao calmo raio de sol que corta o caminho da tempestade, totalmente intocado por ela (SCHOPENHAUER, 2005, §36, 254).

O olhar capaz de encontrar-se com as Ideias dispersas nos fenômenos precisa como que pairar sobre a corrente sem fim de interesses e relações que estendem seus véus sobre os fenômenos, feito grossa camada de chuva, para, intocado por ela, deixar a Ideia apresentar-se livremente. Tal é o modo de consideração genial, assim designado diretamente por conta da compreensão de Schopenhauer da figura do gênio, o artista capaz de apresentar as Ideias em uma obra. Neste contexto, a genialidade seria a preponderância do uso das capacidades cognitivas livres do serviço da Vontade, possibilitando ao gênio a manutenção deste estado tempo o suficiente para posteriormente comunicar a Ideia em obra efetiva ${ }^{3}$. Estariam ai imbuídos também, a possibilidade de perceber mais facilmente a Ideia nos objetos que mais dificultam tal apreensão, permanecendo mudas para os demais, assim como a capacidade de "a partir do pouco que chegou a sua apercepção efetiva, também construir o resto e assim deixar desfilar diante de si quase todas as imagens possíveis da vida" (SCHOPENHAUER, 2001, p. 64).

Temos assim toda uma configuração em que arte e artista adquirem uma importância significativa no que concerne ao conhecimento; o gênio é aquele que abre a comunicabilidade da Ideia a partir da sua contemplação e apresentação em obra, sendo tal obra o meio no qual a Ideia se comunica. Lembremos aqui que genialidade na Metafísica do Belo schopenhauereana dá-se em graus, onde todos os seres humanos possuem um grau, do

\footnotetext{
3، onde o poder do cérebro de formar representações possui um tal excedente de modo que uma imagem pura, distinta e objetiva do mundo externo apresenta-se sem propósitos como algo sem utilidade para as intenções da Vontade, a qual é ainda perturbadora em graus elevados, e pode até mesmo tornar-se prejudicial para estas - então naquele já existe pelo menos a disposição natural para esta anormalidade. Isto é designado pelo nome gênio, o qual indica que algo exterior à Vontade, isto é, ao $\mathrm{Eu}$ ou ego propriamente, um gênio adicionado de fora por assim dizer, parece tornar-se ativo aqui. Para falar sem metáforas, contudo, o gênio consiste na faculdade de conhecimento ter recebido um desenvolvimento consideravelmente mais forte daquele que é requerido para o serviço da Vontade, apenas para o qual ele originalmente veio a existir " (SCHOPENHAUER, 1966, Cap. XXXI, "On genius", p. 377).
} 
contrário não seriam receptivos às experiências estéticas. No gênio tal grau deu-se de forma elevada, lhe conferindo maior facilidade de fuga do princípio de razão, de modo que suas obras são como que seu olhar emprestado aos demais. Em suma, as obras de arte do gênio transmitem ao espectador o modo de consideração genial apresentado acima, onde estes podem participar desse encontro facilitado das Ideias.

Especificando um pouco mais a Metafísica do Belo de Schopenhauer, tem-se aquilo que poderíamos chamar de "classificação metafísica" das artes feita pelo filósofo ${ }^{4}$. Esta classificação dar-se-ia em acordo com a compreensão das Ideias feito graus de objetivação da Vontade, onde haveriam as Ideias vinculadas à natureza inorgânica que se expressam, por exemplo, na pedra, as Ideias da natureza na vida das plantas, dos animais e por fim dos seres humanos. Assim, cada arte é vista schopenhauereanamente segundo a Ideia que ela tem como especificidade expressar; desta forma, a arquitetura seria metafisicamente falando inferior às demais artes por expressar fundamentalmente as Ideias de gravidade e rigidez que são os graus inferiores de objetivação da Vontade, assim indo até a poesia que seria o ponto maior dessa escala valorativa uma vez que tem como finalidade a exposição da Ideia de Humanidade, o grau maior de objetivação da Vontade.

Por isso "toda coisa existente ser bela, pois de um lado, cada uma pode ser considerada de maneira puramente objetiva, exterior a qualquer relação, e, de outro, em cada coisa aparece um grau determinado de objetidade da Vontade, consequentemente uma Ideia" (SCHOPENHAUER, 2001, p. 121). A arte isola a Ideia diante de nós, posto que esta não está dada nos objetos que se enredam sem cessar nas relações, aqui ela dá-se feito imagem intuitiva nítida e significativa, situando-se fora do domínio dos interesses da Vontade. Tal comunicabilidade artística da Ideia comporta ainda uma diferença fundamental em relação à comunicação de simples conceitos.

Os conceitos são obras da faculdade da razão, que nada mais faz do que tornar abstrato aquilo que foi conhecido mais vivamente no particular via representações intuitivas do entendimento. Assim, as representações intuitivas são dadas pelo entendimento e comportam maior riqueza e nelas estamos mais em contato com os atos originários da Vontade, e são estas que a razão conceitualiza após o processo de abstração desta singularidade. As Ideias então são "essencialmente algo da percepção, e deste modo, em sua mais completa determinação, algo inesgotável" (SCHOPENHUAER, 1966, Cap. XXXIV "On the inner nature of Art", p. 408), de modo que não

\footnotetext{
4 “O que situa uma arte em posição superior à outra é antes a Ideia que expõe, e não o material que emprega. Pode inclusive haver hierarquia interna a uma arte: uma estátua de homem será superior a uma estatua de cachorro, posto que exibe uma superioridade advinda da prévia hierarquia das Ideias, instituída quando dos atos originários da Vontade" (BARBOZA, 2001, p. 101)
} 
há um sentido unívoco fechado para a compreensão intuitiva delas, nem mesmo sua comunicação pode ser dada diretamente como ocorre com os conceitos. Sendo estes últimos a fixação comum e abstrata das intuições em "recipientes" universais, sua determinação é ponto comum de compreensão sem diversidade de significados, e podem ser apreendidos por todo individuo dotado de razão; podem ser, "em acordo com todo o seu conteúdo, comunicados fria e desapaixonadamente por palavras" (Ibidem, p. 409). Já as Ideias, que comunicam seu significado a nós em uma linguagem diferenciada, não encontram acolhimento na razão, delas se ocupando a faculdade da imaginação produtivamente concebida, o que Schopenhauer chama de fantasia.

O termo fantasia aparece inicialmente no contexto da discussão sobre o gênio, onde Schopenhauer reconhece que este é o elemento ativo da imaginação do artista responsável por reconhecer a Ideia mesmo nos objetos da natureza cuja objetivação dificulta tal apreensão, lhe permitindo também alcançar as Ideias que não se encontram dadas diretamente em sua percepção empírica. Temos assim a fantasia como algo fundamental para a apreensão da Ideia, pois é o meio através do qual esta preenche plenamente a consciência do sujeito livre da Vontade. Deste modo, ao participar do modo de consideração genial, o espectador também atua ativamente segundo sua imaginação para que a Ideia se lhe apresente, e não mais usando todo seu intelecto tal como no modo de consideração habitual do mundo, ele pode ver-se livre do princípio interessado nas relações fenomenais nas quais se perdem as Ideias. Por fim, Schopenhauer diz:

A Ideia, portanto, fala a cada um apenas de acordo com a medida de sua própria faculdade pura de conhecimento, e também quando está expressa na obra de arte. A Ideia, pois, é comunicável condicionalmente; o conceito, incondicionalmente. Por fim, a diferença entre Ideia e conceito também se pode expressar de maneira comparativa: o conceito é semelhante a um recipiente morto, no qual aquilo que se colocou permanece, efetivamente, lado a lado; o que se colocou por reflexão sintética se deixa também de novo retirar por juízos analíticos, mas não mais. As Ideias, ao contrario, naquele que as apreendeu, desenvolvem representações que, em relação a seu conceito de mesmo nome, são novas; por isso são comparáveis a ao organismo vivo, o qual desenvolve a si mesmo, dotado de força de reprodução, que produz o que nele não estava contido (SCHOPENHAUER, 2001, p. 177).

O lugar em que estas considerações se inserem na Metafísica do Belo de Schopenhauer é o mesmo em que vemos insinuarem-se, de modo diretamente relacionado, questões acerca da crítica de arte. Se as Ideias comunicadas no meio artístico só dizem algo àquele cuja imaginação é livre e criativamente estimulada, libertando-se assim do domínio da Vontade, e isto se dá sempre como uma exceção, temos que as obras do gênio 
permanecerão para a maioria dos seres humanos inacessíveis, como que "livros eternamente fechados" (Ibidem, p. 176).

Para que as Ideias venham apresentar-se diante do espectador, cumpre que este faça uso diferenciado de suas capacidades cognitivas, não mais as condicionando segundo o princípio de razão para que sua faculdade da imaginação possa atuar mais livre e, por conseguinte, criativamente. $\mathrm{O}$ problema dá-se justamente no fato de tal uso diferenciado das faculdades cognitivas ser algo excepcional, de modo que mesmo diante de belas e significativas obras de arte, que facilitam a apreensão de Ideias ${ }^{5}$, encontrarse-ão aqueles cuja faculdade da imaginação não será devidamente despertada à sua atuação responsável pela participação no modo de consideração genial. Tem-se ainda que, mesmo àqueles que alcançaram a apreensão de Ideias a partir de uma obra singular permanece vedado a possibilidade de encontrar a significação última da mesma, dado serem as Ideias dotadas de um caráter de inesgotabilidade de significados ausente dos conceitos, sendo como que "organismos vivos" que continuamente despertam-nos à produção daquilo que nestas não estava contido previamente.

Seria então problemático ao gênio o fato de ter de esperar aprovação de uma maioria que se encontra distanciada do modo de consideração necessário à apreensão da Ideia em cada uma de suas obras e o consequente reconhecimento do mérito das mesmas. Assim,

Quando um mérito genuíno faz sua aparição em seu próprio tempo, os homens são lentos em reconhecê-lo; e isto mostra que eles não entendem, nem fruem, nem realmente apreciam sequer as obras do gênio já longamente reconhecidas as quais eles respeitam e admiram baseados na autoridade (SCHOPENHAUER, 2000, §239, p. 458).

Deste modo, Schopenhauer admite como decorrência natural de suas considerações que o conhecimento das Ideias proporcionado pela obra de arte genial encontra-se sempre sujeito às "perturbações" provocadas pelo princípio de razão, que pode limitá-lo ou até mesmo impedir seu surgimento. Isto segundo os dois pontos destacados acima, um respectivo ao individuo que se coloca frente à obra de arte e que pode permanecer insensível àquilo que nestas sutilmente apresentam-se, as Ideias, e o outro relacionado aos discursos criados para dar conta da mesma, na medida em que podem erroneamente admitir a pretensão de determinar o sentido último

\footnotetext{
5 “A Ideia se nos apresenta mais fácil a partir da obra de arte do que imediatamente a partir da natureza ou efetividade; isso se deve em grande parte ao fato de o artista, que conheceu só a Ideia e não mais a efetividade, também ter reproduzido puramente em sua obra somente a Ideia, destacada da efetividade co todas as suas casualidades perturbadoras; portanto, ele expõe de maneira mais pura do que se encontra na efetividade o essencial e característico desta" (Ibidem, p. 85).
} 
da obra. Assim, acreditamos poder admitir aqui um implícito reconhecimento por parte de Schopenhauer da importância daqueles indivíduos que se ocupam fundamentalmente com o ajuizamento das obras de arte, onde se dá o reconhecimento daquelas que se mostram como profundamente significativas, assim como a produção de discursos que desdobram as Ideias nelas contidas, sendo precisamente aqui que reconhecemos a figura do crítico de arte na Metafísica do Belo.

Schopenhauer mesmo faz referência a tal figura, porém, em um contexto problemático. Segundo o filósofo:

\begin{abstract}
Não se pense que todos [destaque nosso] aqueles indicados por grandes homens, com gestos de respeito profundo, também possuam um conhecimento efetivo do mérito e valor das obras de arte. Tem-se aí mera veneração baseada em lealdade e crença, não a partir da própria avaliação. Nada é mais raro do que o juízo por convicção própria. [...] Assim, cada um dá sua aprovação baseando-se na autoridade, cuja superioridade é acatada silenciosamente (SCHOPENHAUER, 2001, p. 176)
\end{abstract}

Segundo a passagem, vemos que "aqueles indicados por grandes homens" são justamente aqueles que se colocam na posição de críticos das obras de arte, que tomam para si a tarefa de apresentar aos demais "um conhecimento efetivo do mérito e valor das obras de arte". Trata-se de um contexto problemático, como dito, na medida em que Schopenhauer admite que nem todos dentre os "grandes homens" possuem efetivamente tal conhecimento das obras de arte, de modo que o reconhecimento dos mesmos dá-se segundo "mera veneração" por parte daqueles que acatam silenciosamente a autoridade por tais críticos representada. Isto se daria uma vez que "nada é mais raro do que o juízo por convicção própria", ou seja, nada é mais difícil de ser encontrado do que a consideração detida e cuidadosa a partir dos próprios pensamentos e a consequente produção de discursos a eles condizente ${ }^{6}$. Porém, pode-se pensar que tal falta de juízo próprio aplica-se igualmente aos críticos que erroneamente são vistos como "grandes homens", posto que tal veneração equivocada deve-se por conta de estes não terem apreendido corretamente as Ideias que se apresentam através da arte, permaneceram antes na perspectiva do princípio de razão e acabaram por reduzir as obras a meras análises conceituais. Assim, seus juízos acerca do valor de tais obras encontram-se condicionados diretamente

\footnotetext{
${ }^{6}$ Mostra-se importante destacar aqui uma colocação profundamente semelhante feita por Schopenhauer em seu texto Pensar por si mesmo, onde é dito: “Ansiosas e apressadas em resolver questões litigiosas remetendo a autoridades, as pessoas ficam realmente felizes quando podem recorrer não ao seu entendimento e à sua inteligência próprios, de que carecem, mas ao entendimento e à inteligência dos outros. [...] Por isso tais pessoas pretendem contrapor aos argumentos as suas autoridades como um argumentum ad verecundiam [argumento de prova], para em seguida soltarem gritos de vitória" (SCHOPENHUAER, 2012, §10, p. 50).
} 
por imposições arbitrarias e prévias à experiência estética com aquelas, sendo que deveriam antes ser frutos diretos do encontro vívido com cada obra singular e suas respectivas Ideias.

Frisemos então na passagem acima o reconhecimento por parte de Schopenhauer da figura do crítico de arte, assim como sua consideração de que nem todos dentre tais críticos são efetivamente conhecedores do valor artístico das obras. Mostra-se aqui a concessão de Schopenhauer de que haveriam ainda alguns dentre tais críticos que seriam efetivamente merecedores de reconhecimento, e isto em relação à já aludida importância que sua Metafísica do Belo concede a critica de arte, ainda que esta se dê de modo implícito. Em uma significativa passagem de seu texto On judgment, criticism, approbation, and fame, Schopenhauer nos aponta então para a necessidade da presença do crítico de arte, que se compreende plenamente apenas em referência às considerações anteriormente apresentadas. Ele nos diz:

Assim como o sol necessita de um olho para ver sua luz, e a música um ouvido para escutar suas notas, também o valor de todas as obras-primas da arte [...] é condicionado pelo intelecto o qual é parecido e igual a elas e para o qual elas falam. Apenas este intelecto possui a palavra mágica através da qual os espíritos escondidos nestas obras são movimentados e revelam a si mesmos. O homem ordinário coloca-se frente a elas como diante de um armário mágico selado, ou diante de um instrumento o qual ele não sabe como tocar [...]. Consequentemente, para realmente existir e viver, uma obra de arte requer um intelecto sensível [...] (SCHOPENHAUER, 2000, §240, p. 459).

Desta forma, mostra-se consequente pensarmos que a crítica de arte insinua-se sutilmente no pensamento de Schopenhauer como a atividade responsável por desdobrar as Ideias que se apresentam nas obras e que inscrevem em cada uma delas a possibilidade de tal desdobramento. Ou seja, é por ser apresentação de Ideias não esgotáveis conceitualmente, que a arte como que clama pelo desdobramento da riqueza intuitiva inscrita nas obras singulares responsável justamente por fazê-las pertencentes à esfera artística, lhes dando ainda a abertura à sua criticabilidade, tal clamor sendo atendido pelo crítico que se encontra então habilitado a fazê-las sempre dizerem um pouco mais de si mesmas, sem que se chegue com isso a um "dizer" que supostamente lhes daria uma completude final. É o caráter de contínuo acabamento da arte, dado ser a intuição o lugar em que esta encontra-se com as Ideias que formalizadas apresentam-se em obras, que impõe ao exercício crítico a tarefa de participar da construção de sentidos possíveis cujos desdobramentos não podem ser previstos de antemão, e serão continuados pelos exercícios criticos posteriores bem como pela participação no modo de consideração genial por parte dos espectadores. 
Assim, o lugar ocupado pela obra de arte na Metafísica do Belo schopenhaueriana, qual seja, a de medium facilitador para o conhecimento das Ideias, acaba igualmente por conferir a estas a caracteristica de carregarem sempre em si uma "promessa" de sentido somente atendida por uma disposição subjetiva livre do princípio de razão, um intelecto mais "sensível" às mesmas, de modo que caberia à crítica de arte criar as condições que facilitassem tal disposição no espectador. Tal promoção de abertura ao encontro com as Ideias emerge nos discursos críticos, na medida em que trazem à comunicação a riqueza intuitiva das obras e garantem a continuidade do processo de construção do sentido que tais Ideias carregam e que dá-se privilegiadamente na própria produtividade da crítica.

\section{Referências bibliográficas}

ATWELL, John. Schopenhauer on the Character of the World: The Metaphysics of Will. Berkeley and Los Angeles: University of California Press, 1995.

BARBOZA, Jair. A Metafísica do Belo de Arthur Schopenhauer. São Paulo: UNESP, 2001.

SCHOPENHAUER, Arthur. The world as will and representation, Vol. 2. Translated by E. F. J. Payne. New York: Dover Publications, 1966.

. "On judgment, criticism, approbation, and fame". In: SCHOPENHAUER, Arthur. Parerga and Paralipomena Vol. 2. Translated by E. F. J. Payne. Oxford: Oxford University Press, 2000.

Metafísica do Belo. Tradução, apresentação e notas por Jair Barboza. São Paulo: UNESP, 2001.

O mundo como vontade e como representação. Tradução, apresentação, notas e índices por Jair Barboza. São Paulo: UNESP, 2005.

A arte de escrever. Tradução organização, prefácio e notas por

Pedro Süssekind. Porto Alegre: L\&PM, 2009. 